\title{
HISTÓRIA E SAÚDE: AS INTERFACES ENTRE A AÇÃO PÚBLICA, AS INICIATIVAS DA SOCIEDADE CIVIL E AS INOVAÇÕES TECNOLÓGICAS
}

\author{
Vanessa Lana ${ }^{1}$ \\ Luiz Antônio Teixeira²
}

Recebido em: 24/04/2021

Aprovado em: 26/05/2021

A reflexão sócio-histórica sobre a saúde, em seus múltiplos aspectos, está diretamente relacionada à ampliação da agenda histórica experenciada desde fins do século XX, que contribuiu para a incorporação de novos temas e perspectivas de abordagem. Com a ampliação do universo da investigação histórica nas análises sobre saúde, é possível observar um movimento de inserção das dinâmicas locais e regionais aos circuitos nacionais e globais, o que refletiu na incorporação de espacialidades, atores e temáticas. A história das ações e políticas em saúde nos últimos anos, no âmbito das renovações historiográficas, incorporou diferentes tipologias de fontes históricas, impulsionando a percepção dos mais variados sujeitos imersos nesses processos e uma ampliação da análise das experiências de adoecimento e das políticas em saúde, fomentando o debate com diferentes campos do conhecimento, como a sociologia, a demografia, a saúde coletiva e a ciência política.

Nesse percurso, a perspectiva histórica vem trazendo inegáveis contribuições para o campo da saúde. A compreensão dos processos históricos no domínio da saúde e das doenças, pensado como um campo de saberes e práticas interdisciplinares, possibilita uma postura crítica acerca dos diversos elementos que compõem esses domínios, como crenças, saberes, práticas, arranjos institucionais, concepções políticas, culturais e as teias de relações que envolvem a

\footnotetext{
${ }^{1}$ Doutora e Pós-Doutora em História das Ciências pela Casa de Oswaldo Cruz / FIOCRUZ. Professora do Departamento de História da Universidade Federal de Viçosa e do Mestrado em Patrimônio Cultural, Paisagens e Cidadania. E-mail: vanessalana@ufv.br. ORCID ID: https://orcid.org/0000-0002-1950-1206.

${ }^{2}$ Doutor em História Social. Pesquisador no Departamento de Pesquisa e no Programa de Pós-graduação em História das Ciências e da Saúde, da Casa de Oswaldo Cruz / FIOCRUZ. Professor no Programa de Pós-graduação em Saúde da Criança e da Mulher, do Instituto Fernandes Figueira. Pesquisador de produtividade pelo CNPq. Cientista do Nosso Estado pela Faperj. E-mail: luiztei3@gmail.com. ORCID ID: https://orcid.org/0000-0001$\underline{8871-0928 .}$.
} 
construção de aparatos de atenção e cuidados com a saúde (PERDIGUERO, et. al., 2001). A pesquisa histórica possibilita ainda a reflexão sobre ações contemporâneas no campo da saúde, através da identificação de padrões, permanências e rupturas em diferentes realidades e compreensões contextualizadas aos âmbitos social, político e econômico, permitindo lidar com complexidades, analisando movimentos e tendências culturais (BERRIDGE, 2000; FEE and BROWN, 1997).

De forma simétrica, a História vem se beneficiando desse objeto de análise, que favorece reflexões ricas e circunstanciadas sobre diferentes aspectos que vão do cotidiano às amplas estruturas sociais. As questões que envolvem os debates sobre discursos, práticas e instituições em saúde estão vinculadas à organização social, sendo dimensões determinantes dos componentes que impactam no cotidiano das sociedades.

História e saúde, portanto, é um binômio que incorpora diferentes formulações, objetos e metodologias. Entre eles, as questões relativas às políticas públicas de assistência, instituições e iniciativas da sociedade civil organizada frente a diferentes agravos tornam-se centrais por se mostrarem como ferramentas potentes para a compreensão da relação entre saúde e transformações sociais mais amplas. A concepção das questões sobre saúde como um sistema social abriu caminhos para a percepção de que mesmo aspectos de ordem técnica do âmbito da medicina e políticas em saúde são influenciados e moldados por aspectos culturais, intelectuais e de estruturas institucionais compartilhadas por comunidades específicas (ROSENBERG, 1989).

O binômio saúde-doença, portanto, não pode ser interpretado da mesma forma ao longo das diferentes épocas, pois os acontecimentos associados ao mesmo produzem uma historicidade que se diferencia nas diversas temporalidades e espacialidades. Nas novas narrativas acerca dessas temáticas foram incorporadas categorias como assistência, gênero e representação, a problematização do papel do Estado e suas instituições, análises dos espaços e personagens relacionados a processos de cura, incluindo as práticas de cura alternativas, que corriqueiramente estiveram à margem da história.

Representativos desse campo de investigação, os artigos que compõem o Dossiê História e Saúde: as interfaces entre a ação pública, as iniciativas da sociedade civil e as inovações tecnológicas refletem a variedade de temáticas, usos de fontes e possibilidades de diálogo com diversas metodologias. Ao dialogarem com diferentes perspectivas da pesquisa histórica, os trabalhos apresentados evidenciam a expansão dos estudos sobre história e saúde no Brasil, em suas interfaces com a ação pública, políticas de saúde, iniciativas da sociedade civil, tradições culturais e inovações tecnológicas. 
Iniciando a discussão, o trabalho de Keila Auxiliadora Carvalho e Ramon Feliphe Souza, Por uma história da saúde do Vale do Jequitinhonha: Reflexões sobre práticas Populares de Cura, analisa as práticas populares de cura no Vale do Jequitinhonha, em Minas Gerais, mais especificamente nos municípios de Diamantina e Couto de Magalhães de Minas (antigo distrito de Diamantina). O argumento dos autores é de que as práticas populares de cura são elementos presentes na sociedade e na constituição da identidade regional. Nesse sentido, percorrendo temporalidades do século XIX e início do século XX, discutem como os agentes de cura foram alvo dos discursos de crítica da medicina científica no Brasil. Ao analisar o contexto de Diamantina, apontam para o envolvimento de curadores em processos criminais que pretendiam desqualificar suas práticas, assim como a repressão a agentes de cura não oficiais, que foram alvo de críticas em jornais diamantinenses no início do século XX. A partir da metodologia da História Oral, destacam a permanência das práticas populares de cura na região, especialmente benzeções e o uso de plantas medicinais.

Num salto temporal, com foco nas políticas públicas em saúde, o artigo A Atenção Primária à Saúde no SUS: o processo de construção de uma política nacional (1990 - 2006), da autoria de Carlos Henrique Assunção Paiva, discute a construção de uma política nacional de atenção primária à saúde no SUS, desde sua constituição em 1990 até 2006, quando foi publicada a primeira Política Nacional de Atenção Básica do país. A narrativa percorre o caminho que tem início nas estratégias de consolidação do SUS, passando pela criação do Programa de Agentes Comunitários de Saúde (PACS), discutindo os desdobramentos do PACS, precursor do Programa Saúde da Família (PSF) criado em 1994, e finaliza no processo de formulação e institucionalização da primeira Política Nacional de Atenção Básica (PNAB). O foco da análise passa pela identificação dos principais atores relacionados com as ações de atenção primária e as mobilizações políticas que foram necessárias para sua efetivação. $\mathrm{O}$ argumento é que, nos anos 2000, abriu-se uma fase promissora para a Atenção Primária à Saúde (APS) no Brasil, ampliando-se o consenso técnico e político acerca do papel da APS na organização das instituições e na reorganização do modelo de atenção à saúde.

Na discussão sobre a trajetória de políticas de saúde sobre uma doença em específico, no caso, o câncer de mama, que também será o foco dos próximos três artigos desse dossiê, o trabalho de Thaislayne Nunes de Oliveira e Mônica de Castro Maia Senna, Politicas de controle do câncer de mama no Brasil, se propõe a analisar a trajetória histórica das políticas de controle do câncer de mama feminino no Brasil, com o argumento de que o desenvolvimento das estratégias para os cuidados com a doença é inerente ao contexto de desenvolvimento da política de saúde brasileira. $\mathrm{O}$ estudo traça um percurso que vai da segunda metade do século $\mathrm{XX}$ ao 
início do século XXI, observando as incorporações legais que impactaram na organização das políticas sobre o câncer de mama no país e as medidas preventivas correlacionadas, analisando as legislações e normativas implantadas e dados relativos às estatísticas de saúde e estimativas disponibilizadas nas plataformas DATASUS e INCA. A análise constata um avanço na estruturação das legislações, além da implantação de programas e sistemas relacionados à doença, que favorecem a detecção precoce, mas aponta para um cenário ainda caracterizado por um significativo número de casos que evoluem a óbito e repleto de fragilidades e desafios.

$\mathrm{Na}$ discussão sobe o processo de criação dos primeiros registros de câncer no Brasil entre as décadas de 1960 e 1980, Luiz Alves Araújo Neto, em Quantificar, padronizar e planejar: registros de câncer e atenção oncológica no Brasil (1960-1980), atenta aos debates sobre quantificação, padronização e planejamento da atenção oncológica relacionados à estruturação desses serviços. O autor argumenta que a trajetória de criação dos primeiros serviços, em São Paulo e Pernambuco, serviu de modelo para diversas iniciativas em âmbitos regionais e nacional, incluindo a tentativa de estabelecer um plano nacional para a fundação de registros de câncer nos anos 1970, comandado pela Divisão Nacional de Câncer. A organização desses serviços esteve relacionada ao princípio de que o planejamento da atenção oncológica demandava do conhecimento sobre a situação epidemiológica do câncer no Brasil, estando atrelado ao desenvolvimento da epidemiologia das doenças crônicas como campo disciplinar e à introdução e consolidação dos estudos de morbidade. Tais estudos se mostravam fundamentais para o planejamento de estratégias de redução do número de mortes e de novos casos da doença.

Em, Câncer de mama: uma preocupação para a mulher cearense, 1950 a 1980, Thayane Lopes Oliveira analisa a construção do câncer de mama como uma preocupação para a mulher cearense e um problema médico e sanitário no estado do Ceará entre as décadas de 1950 e 1980, através dos discursos dos médicos locais do período, veiculados por publicações em revistas médicas, como a Revista Brasileira de Cancerologia, a Revista Ceará Médico e jornais locais. Ao levantar os discursos da relação entre câncer e modernidade, o trabalho aponta para uma grande movimentação dos médicos no sentido de alçar a doença como mais uma preocupação para a mulher cearense. A partir de dados epidemiológicos, esses profissionais demonstravam que a incidência do câncer de mama crescia e se tornava um problema médico no estado, num cenário permeado por controvérsias. Se o câncer era fruto de um processo de transição epidemiológica que significou a melhoria das condições sociais, o aumento da incidência de alguns tipos de câncer era um sintoma do desenvolvimento social e econômico do país ou da cidade, como no caso de Fortaleza. 
Numa discussão sobre a sociedade civil e a organização de associações de pacientes, ainda discutindo o câncer de mama como objeto de investigação histórica, Vanessa Lana e Luiz Antônio Teixeira, em $O$ câncer de mama e a sociedade civil: as ações da FEMAMA na regulamentação temporal para diagnóstico e tratamento da doença no Brasil, analisam a atuação da Federação Brasileira de Instituições Filantrópicas de Apoio à Saúde da Mama, FEMAMA, enquanto associação de pacientes com câncer de mama com foco no ativismo político e advocacy. Tendo como base o conceito de biomedicalização, discutem as ações da FEMAMA no processo de aprovação e implementação da legislação de regulamentação temporal para diagnóstico e tratamento em câncer de mama no Brasil. As associações de advocacy, como a FEMAMA, ao possibilitarem parcerias e alianças políticas entre diversos atores sociais, contribuíram para a garantia do direito das mulheres ao diagnóstico precoce e melhor qualidade de vida para as que vivenciam a experiência da doença. A atuação da FEMAMA foi efetiva na aprovação e regulamentação dos marcos temporais dos principais fatores relacionados ao estadiamento do câncer de mama e diminuição das possibilidades de cura. Historicamente, o atraso no diagnóstico e tratamento estão relacionados às altas taxas de mortalidade pela doença nos países em desenvolvimento. Assim, atuar nessas questões se mostrava como uma das principais estratégias de garantir os direitos e interesses das pacientes com câncer de mama, um dos princípios fundamentais das ações em advocacy.

Fechando o dossiê, numa discussão ainda sobre associativismo contemporâneo, tendo o ativismo e o engajamento político como elementos norteadores das ações das associações de pacientes, em Narrativas sobre a síndrome pós-pólio em associações de pacientes do Brasil e da Espanha nos meios digitais, Danielle Souza Fialho da Silva discute as narrativas construídas e divulgadas por associações de pacientes no Brasil e Espanha sobre a Síndrome Pós-pólio. As associações trabalhadas são a Associação Brasileira de Síndrome Pós-poliomielite (Abraspp) e a Asociación Afectados de Polio y Síndrome Post-polio, numa proposta de discussão tecida a partir dos meios digitais de ambas, na divulgação de informações sobre a síndrome, tomando para o coletivo a co-elaboração de políticas inclusivas e defesa dos direitos de pessoas com deficiência. Ao analisar as narrativas sobre a doença que são divulgadas pelas associações, a autora buscou perceber como as mesmas tomam como apoio o saber especializado para ampliar a base de pesquisa e conhecimento, divulgando informações sobre eventos médico-científicos, artigos e conteúdos informativos.

Diante desse breve percurso sobre o conteúdo do Dossiê História e Saúde: as interfaces entre a ação pública, as iniciativas da sociedade civil e as inovações tecnológicas, percebemos a multiplicidade de abordagens e temáticas que esse campo de conhecimento possibilita. Os 
trabalhos aqui apresentados circulam pela historicidade das práticas e discursos científicos, pelas associações civis, instituições e políticas públicas, por perspectivas teórico-metodológicas e pelas experiências das doenças em múltiplas facetas, apontando para elementos da relação com o poder público, a sociedade e transformações no cotidiano das populações. A diversidade de perspectivas e a interdisciplinaridade presente nos textos se apresenta como indicativo de que, além da multiplicidade de abordagens possíveis, ainda há um amplo campo a ser trabalhado, pesquisado e discutido.

A riqueza de fontes, metodologias e espacialidades analisadas oferece ao leitor um amplo leque de perspectivas e possibilidades para compreensão da temática e para o próprio fortalecimento dos estudos em História e Saúde no país. O presente dossiê, ao contemplar diferentes espacialidades e temporalidades, constitui uma amostra da vitalidade dos estudos em História e Saúde que vêm sendo desenvolvidos no Brasil.

Desejamos uma excelente leitura!

Vanessa Lana e Luiz Antônio Teixeira.

\section{Referências bibliográficas}

BERRIDGE, Virgínia. History in public health: who needs it? The Lancet, Reino Unido, v. 356, p. 1923-1925, dez. 2000.

FEE, Elizabeth and BROWN, Theodore. Editorial: Why history? American Journal of Public Health, v.87, n.11, p.1763-1764, 1997.

PERDIGUERO, E.; BERNABEU, J.; HUERTAS, R.; RODRIGUEZ-OCAÑA, E. History of health, a valuable tool in public health. Journal of Epidemiological Community Health, v. 55 , n. 9 , p. 667-673, 2001.

ROSENBERG, Charles. Disease in History: Frames and Framers. The Milbank Quarterly, v. 67 , n. 1 , p. $1-15,1989$. 